\title{
Equilibrium properties in the duopolistic price-setting market as determinants for the term structure of interest rates: A game-theoretic approach
}

\author{
Shigeru Nishiyama*
}

Department of Business Administration, Kyushu International University, Kitakyushu, Japan

\author{
Keywords: \\ Term structure of interest \\ rates \\ Game theory \\ Price-setting game \\ Bertrand game \\ Stackelberg game
}

\begin{abstract}
The aim of this paper is to provide an alternative view on the term structure of interest rates in the light of game theory. First, the pricing of short- and long-term interest rates is formulated as an oligopolistic price-setting game in the financial market. Second, the equilibria in Bertrand and Stackelberg games are compared under a set of reasonable assumptions consistent with the distinctive features of the financial market. Third and finally, short- and long-term interest rates and their optimization are analytically investigated by means of applying the equilibrium properties of these games. The crucial roles of reaction function in forming the term structure are also emphasized.
\end{abstract}

(c) 2016 The Author(s). Published by TAF Publishing.

Received: 28 March 2016

Accepted: 10 June 2016

Published: 12 August 2016

\section{INTRODUCTION}

The term structure of interest rates, the question of how interest rates with different maturities are priced, is recognized as one of the fundamental issues in financial economics. Though there is a vast amount of discussion on the issue, including (Sargent, 1972) and (Cox, Ingersoll \& Ross, 1985) among leading studies, in almost all of the literature is the absence of reflection about its characteristics as an oligopolistic game with respect to maturities or terms. The present paper addresses these characteristics, which provide another way to study the issue in an alternative view. More specifically, the paper

\footnotetext{
*Corresponding author: Shigeru Nishiyama

E-mail: shigeru@hotmail.co.jp
}

focuses on the term structure of interest rates as a pricesetting game, by means of applying the theories and concepts of Bertrand and Stackelberg games, originally developed by Cournot (1838), Bertrand (1883) and Stackelberg (1934) and more recently by Matsumura (1998), Okuguchi (1999), Vives (2001) and Puu \& Sushko (2002) in the light of the paper's concern, as well as Freixas \& Jean-Charles (2008) and Matthews \& Thompson (2008) as general description of the relationship between game equilibria and interest rates in banking. Considering a financial market with short- and long-term funds, which are non-cooperative between themselves, the paper clarifies the conditions underlying the optimization of short- and long-term interest rates and grasps the effect of these conditions on the term structure of interest rates in view of the equilibrium properties of the price-setting games. The following sections present the essence of the 
paper's model and the main results obtained from analysis using the model.

\section{The Price-Setting Games on Interest Rates (a) Payoff Function}

Let there be a financial market where short- and long-term funds are traded. The terms of traded funds are identified by $t \in\{s, l\}$. The payoff (profit) upon the funds of each term is given as:

$\pi_{t}=\pi_{t}\left(r_{t}, r_{\tau}\right) \equiv r_{t} y_{t}\left(r_{t}, r_{\tau}\right) t, \tau \in\{s, l\} ; t \neq \tau$,

where $r_{t} \in[0,+\infty]$ denotes the interest rate on fund with term $t$, and $y_{t}: R_{+}^{2} \rightarrow R_{+}$is the demand function for term $t$ fund. $y_{t}$ is assumed to be twice continuously differentiable.

\section{(b) Bertrand Game}

The interest rate upon the fund with each term $t \in\{s, l\}$ is determined such that the first order condition

$$
\frac{\partial \pi_{t}}{\partial r_{t}}=y_{t}+r_{t} \frac{\partial y_{t}}{\partial r_{t}}=0 t \in\{s, l\}
$$

is satisfied. In order that (2) holds, in the neighborhood of equilibrium

$$
\frac{\partial y_{t}}{\partial r_{t}}<0
$$

where the " $A$ " added ahead of the equation number refers to "assumption." The second order condition

$\frac{\partial^{2} \pi_{t}}{\partial r_{t}^{2}}=2 \frac{\partial y_{t}}{\partial r_{t}}+r_{t} \frac{\partial^{2} y_{t}}{\partial r_{t}^{2}}<0 \quad t \in\{s, l\}$

is assumed to be satisfied. Solving (2) with respect to $r_{t}$, the reaction function of fund with term $t$ is obtained as:

$r_{t} \equiv \phi_{t}\left(r_{\tau}\right)=\underset{r_{t} \geq 0}{\arg \max }\left[r_{t} y_{t}\left(r_{t}, r_{\tau}\right)\right] t, \tau \in\{s, l\} ; t \neq \tau$,

where

$\phi_{t}^{\prime}\left(r_{\tau}\right)=-\left(\frac{\partial y_{t}}{\partial r_{\tau}}+r_{t} \frac{\partial^{2} y_{t}}{\partial r_{t} \partial r_{\tau}}\right) /\left(2 \frac{\partial y_{t}}{\partial r_{t}}+r_{t} \frac{\partial^{2} y_{t}}{\partial r_{t}^{2}}\right) \gtrless 0$

as $\frac{\partial y_{t}}{\partial r_{\tau}}+r_{t} \frac{\partial^{2} y_{t}}{\partial r_{t} \partial r_{\tau}} \gtrless 0$.

At the Bertrand equilibrium, term $t$ interest rate $r_{t}^{B}$ is specified as $r_{t}^{B} \equiv \phi_{t}\left(r_{\tau}^{B}\right)$, where $t, \tau \in\{s, l\} ; t \neq \tau$, and the payoff $\pi_{t}^{B}$ is

$$
\pi_{t}^{B}=\pi_{t}\left(r_{t}^{B}, r_{\tau}^{B}\right) t, \tau \in\{s, l\} ; t \neq \tau .
$$

As a common stability condition to ensure the existence and uniqueness of a set of equilibrium solutions, assume now that
If $\left(\phi_{t}\left(r_{\tau}\right), r_{\tau}\right) \in R_{++}^{2}$, then $0<\left|\phi_{t}^{\prime}\left(r_{\tau}\right)\right|<1 . \quad t, \tau \in\{s, l\} ; t \neq \tau$.

\section{(c) Stackelberg Game}

Under the Stackelberg structure, short-term interest rate is assumed to be determined by taking account of the reaction function of long-term rate, acting as the leader of price-setting game in the market. In other words, shortterm interest rate provides itself as a reference rate for long-term rate. Formally, short-term interest rate maximizes its payoff (profit) $\pi_{s}=\pi_{s}\left(r_{s}, \phi_{l}\left(r_{s}\right)\right)$ with respect to itself.

The first order condition to be satisfied is:

$\frac{d \pi_{s}}{d r_{s}}=y_{s}+r_{s}\left(\frac{\partial y_{s}}{\partial r_{s}}+\frac{\partial y_{s}}{\partial r_{l}} \phi_{l}^{\prime}\left(r_{s}\right)\right)=0$.

Assume that the second order condition

$\frac{d^{2} \pi_{s}}{d r_{s}^{2}}=2\left(\frac{\partial y_{s}}{\partial r_{s}}+\frac{\partial y_{s}}{\partial r_{l}} \phi_{l}^{\prime}\left(r_{s}\right)\right)+r_{s}\left[\frac{\partial^{2} y_{s}}{\partial r_{s}^{2}}+2 \frac{\partial^{2} y_{s}}{\partial r_{s} \partial r_{l}} \phi_{l}^{\prime}\left(r_{s}\right)+\frac{\partial^{2} y_{s}}{\partial r_{l}^{2}}\left(\phi_{l}^{\prime}\left(r_{s}\right)\right)^{2}\right]<0$

(A10)

holds. Hence the payoff (profit) on short-term fund is specified as

$\pi_{s}^{L}=\pi_{s}^{L}\left(r_{s}\right) \equiv \pi_{s}\left(r_{s}, \phi_{l}\left(r_{s}\right)\right) \equiv r_{s} y_{s}\left(r_{s}, \phi_{l}\left(r_{s}\right)\right)$,

which is strictly concave under the assumption (A10). At the Stackelberg equilibrium, short-term interest rate with the Stackelberg leadership, $r_{s}^{L}$, is obtained as:

$r_{s}^{L} \equiv \underset{r_{s} \geq 0}{\arg \max } \pi_{s}^{L}\left(r_{s}\right)$.

On the other hand, long-term interest rate as the follower price in the game, $r_{l}^{F}$, is determined by its reaction function:

$r_{l}^{F} \equiv \phi_{l}\left(r_{s}^{L}\right)$.

The Equilibria in Bertrand and Stackelberg Games and Short and Long Term Interest Rates

This section investigates how short- and long-term interest rates are determined in the market, and compares these rates in the light of the equilibrium properties of Bertrand and Stackelberg price-setting games.

From (9), (A10), (11) and (12), obviously

$\left[\pi_{s}^{L}\left(r_{s}^{L}\right)\right]^{\prime}=0$.

Taking account of the first order condition for the Bertrand equilibrium (2),

$\left[\pi_{s}^{L}\left(r_{s}^{B}\right)\right]^{\prime}=r_{s}^{B} \frac{\partial y_{s}}{\partial r_{l}} \phi_{l}^{\prime}\left(r_{s}^{B}\right)$ 
is obtained. Since (A10) holds, $\pi_{s}^{L}\left(r_{s}\right)$ is a strictly concave function,

$$
r_{s}^{L} \gtrless r_{s}^{B} \quad \text { if }\left[\pi_{s}^{L}\left(r_{s}^{B}\right)\right]^{\prime} \gtrless 0 .
$$

Assuming identical demand function for short- and longterm funds to advance the analysis,

$$
\frac{\partial y_{s}}{\partial r_{s}}=\frac{\partial y_{l}}{\partial r_{l}} \text {. }
$$

Here, the following two cases are possible according to the sign of $\frac{\partial y_{t}}{\partial r_{\tau}}(t, \tau \in\{s, l\} ; t \neq \tau)$ : (I) Short- and long-term funds are substitutive $\left(\frac{\partial y_{t}}{\partial r_{\tau}}>0\right)$ or (II) complementary $\left(\frac{\partial y_{t}}{\partial r_{\tau}}<0\right)$

(I) $\frac{\partial y_{t}}{\partial r_{\tau}}>0 \quad t, \tau \in\{s, l\} ; t \neq \tau$

Take the case that short- and long-term funds are substitutive. From (15), (16) and (18)

$$
r_{s}^{L} \gtrless r_{s}^{B} \text { as } \phi_{l}^{\prime}\left(r_{s}^{B}\right) \gtrless 0 .
$$

Under the assumption of identical demand function,

$$
r_{s}^{B}=r_{l}^{B}=r^{B} .
$$

from (2) and (A17). (20) provides an essential benchmark for the model. On the benchmark of (20), in the light of (A8) and (19),

$$
\left\{\begin{array}{l}
r^{B}<r_{l}^{F}<r_{s}^{L} \\
r_{s}^{L}<r^{B}<r_{l}^{F}
\end{array} \quad \text { as } \quad \phi_{l}^{\prime}\left(r_{s}\right) \gtrless 0 .\right.
$$

(II) $\frac{\partial y_{t}}{\partial r_{\tau}}<0 \quad t, \tau \in\{s, l\} ; t \neq \tau$

Next, the case that short- and long-term funds are complementary. In the same way as the case of (18), from (15), (16) and (22),

$$
r_{s}^{L} \lessgtr r_{s}^{B} \quad \text { as } \quad \phi_{l}^{\prime}\left(r_{s}^{B}\right) \gtrless 0 .
$$

Thus,

$$
\left\{\begin{array}{l}
r_{s}^{L}<r_{l}^{F}<r^{B} \\
r_{l}^{F}<r^{B}<r_{s}^{L}
\end{array} \text { as } \quad \phi_{l}^{\prime}\left(r_{s}\right) \gtrless 0 .\right.
$$

Let us summarize the analysis up to here. Facing identical demand for short- and long-term funds, Bertrand short- and long-term interest rates provide a flat yield curve in the duopolistic financial market with respect to terms. The Stackelberg structure between short- and longterm interest rates generates the difference therein. In the financial market where short- and long-term funds are substitutive, if short-term interest rate has the leadership in interest rate pricing and long-term rate moves in the same direction as short-term rate, short-term rate is higher than long-term rate. The market thus has a downward-sloping (inverted) yield curve. If long-term interest rate moves inversely, short-term rate is lower than long-term rate, forming an upward-sloping (normal) yield curve, which is always across the flat yield curve of the market. On the other hand, in the market with complementary short- and long-term funds, if long-term rate moves in the same direction as short-term rate, shortterm rate is lower than long-term rate, and their yield curve slopes upward. Otherwise, if long-term interest rate moves inversely to short-term rate, short-term interest rate is higher than long-term rate, providing a downwardsloping yield curve, always across the flat yield curve in the market.

\section{Profit and Fund Volume under the Term Structure of Interest Rates}

This section compares the volumes of short- and long-term funds and profits on them at equilibria. First examined are the equilibrium profits which are applicable to be accepted as profits gained from short- and long-term interest rates with the main patterns of the term structure.

Taking account that $\pi_{s}^{L}\left(r_{s}\right)$ is a strictly concave function on (9) and (A10), from (14) and (15),

$\pi_{s}^{L}\left(r_{s}^{L}\right)=\pi_{s}\left(r_{s}^{L}, r_{l}^{F}\right) \equiv \pi_{s}^{L}>\pi_{s}^{L}\left(r^{B}\right)=\pi_{s}\left(r_{s}^{B}, r_{l}^{B}\right)=\pi_{l}\left(r_{l}^{B}, r_{s}^{B}\right) \equiv \pi^{B}$

Regardless of the sign of $\phi_{l}^{\prime}\left(r_{s}\right)$ and $\frac{\partial y_{t}}{\partial r_{\tau}}, t, \tau \in\{s, l\} ; t \neq \tau$

Applying the mean value theorem,

$$
\begin{aligned}
\pi_{s}\left(r_{s}^{L}, r_{l}^{F}\right) & =\pi_{s}\left(r_{l}^{F}, r_{s}^{L}\right)+\left(r_{s}^{L}-r_{l}^{F}\right) \frac{\partial \pi_{s}}{\partial r_{s}}+\left(r_{l}^{F}-r_{s}^{L}\right) \frac{\partial \pi_{s}}{\partial r_{l}} \\
& =\pi_{s}\left(r_{l}^{F}, r_{s}^{L}\right)+\left(r_{s}^{L}-r_{l}^{F}\right)\left(\frac{\partial \pi_{s}}{\partial r_{s}}-r_{s} \frac{\partial y_{s}}{\partial r_{l}}\right)
\end{aligned}
$$

and

$$
\begin{aligned}
\pi_{s}\left(r_{l}^{F}, r_{s}^{L}\right) & =\pi_{s}\left(r_{s}^{B}, r_{l}^{B}\right)+\left(r_{l}^{F}-r_{s}^{B}\right) \frac{\partial \pi_{s}}{\partial r_{s}}+\left(r_{s}^{L}-r_{l}^{B}\right) \frac{\partial \pi_{s}}{\partial r_{l}} \\
& =\pi_{s}\left(r^{B}, r^{B}\right)+\left(r_{s}^{L}-r^{B}\right)\left(\frac{\partial \pi_{s}}{\partial r_{s}} \phi_{l}^{\prime}+r_{s} \frac{\partial y_{s}}{\partial r_{l}}\right) .
\end{aligned}
$$

In the case of $\frac{\partial y_{t}}{\partial r_{\tau}}>0$, if $\phi_{l}^{\prime}\left(r_{s}\right)>0, \frac{\partial \pi_{s}}{\partial r_{s}}<0$ for any intermediate values between $r_{s}^{L}$ and $r_{l}^{F}$, in the light of (2), (A4) and $r^{B}<r_{l}^{F}<r_{s}^{L}$ in (21). Thus, from (26),

$$
\pi_{s}\left(r_{s}^{L}, r_{l}^{F}\right)=\pi_{s}^{L}<\pi_{s}\left(r_{l}^{F}, r_{s}^{L}\right)=\pi_{l}\left(r_{l}^{F}, r_{s}^{L}\right) \equiv \pi_{l}^{F}
$$

is obtained. (25) and (28) yield

$$
\pi^{B}<\pi_{s}^{L}<\pi_{l}^{F} .
$$


Meanwhile, if $\phi_{l}^{\prime}\left(r_{s}\right)<0, \frac{\partial \pi_{s}}{\partial r_{s}}<0$ for any intermediate values between $r_{l}^{F}$ and $r^{B}$, in the light of (2), (A4) and $r^{B}<r_{l}^{F}$ in (21). In view of (27),

$$
\pi_{l}\left(r_{l}^{F}, r_{s}^{L}\right)=\pi_{l}^{F}<\pi^{B},
$$

which coupled with (25) leads to

$$
\pi_{l}^{F}<\pi^{B}<\pi_{s}^{L} .
$$

On the other hand, in the case of $\frac{\partial y_{t}}{\partial r_{\tau}}>0$, from (2), (A4) and $r_{s}^{L}<r_{l}^{F}<r^{B}$ or $r_{l}^{F}<r^{B}<r_{s}^{L}$ as the sign of $\phi_{l}^{\prime}\left(r_{s}\right)$ in (24),

$$
\pi^{B}<\pi_{s}^{L}<\pi_{l}^{F}, \text { if } \phi_{l}^{\prime}\left(r_{s}\right)>0
$$

and

$$
\pi_{l}^{F}<\pi^{B}<\pi_{s}^{L}, \text { if } \phi_{l}^{\prime}\left(r_{s}\right)<0,
$$

by the same manner as (29) and (31).

Thus,

$$
\left\{\begin{array}{l}
\pi^{B}<\pi_{s}^{L}<\pi_{l}^{F} \\
\pi_{l}^{F}<\pi^{B}<\pi_{s}^{L}
\end{array} \quad \text { as } \quad \phi_{l}^{\prime}\left(r_{s}\right) \gtrless 0 \quad \text { or } \quad \frac{\partial y_{t}}{\partial r_{\tau}}+r_{t} \frac{\partial^{2} y_{t}}{\partial r_{t} \partial r_{\tau}} \gtrless 0\right.
$$

irrespective of the sign of $\frac{\partial y_{t}}{\partial r_{\tau}}$.

Next, the volumes of short- and long-term funds at equilibria. As mentioned above on the equilibrium profits, these equilibrium volumes are regarded as the volumes of short- and long-term funds under the term structure patterns.

To obtain a unique set of equilibrium fund volumes, additional assumptions are required on demand functions. Hereafter this paper focuses on the simplest case where demand functions for short- and long-term funds are identical, being globally linear and symmetrical with respect to the two types of interest rates, without loss of methodological generality.

Consider the two cases based on the sign of $\frac{\partial y_{t}}{\partial r_{\tau}}$ $(t, \tau \in\{s, l\} ; t \neq \tau)$ as in the third section.

(I) $\frac{\partial y_{t}}{\partial r_{\tau}}>0 \quad t, \tau \in\{s, l\} ; t \neq \tau$

Using the mean value theorem,

$$
\begin{aligned}
y_{s}\left(r_{s}^{L}, r_{l}^{F}\right) & =y_{s}\left(r_{l}^{F}, r_{s}^{L}\right)+\left(r_{s}^{L}-r_{l}^{F}\right) \frac{\partial y_{s}}{\partial r_{s}}+\left(r_{l}^{F}-r_{s}^{L}\right) \frac{\partial y_{s}}{\partial r_{l}} \\
& =y_{l}\left(r_{l}^{F}, r_{s}^{L}\right)+\left(r_{s}^{L}-r_{l}^{F}\right)\left(\frac{\partial y_{s}}{\partial r_{s}}-\frac{\partial y_{s}}{\partial r_{l}}\right),
\end{aligned}
$$

$$
\begin{aligned}
y_{s}\left(r_{s}^{L}, r_{l}^{F}\right) & =y_{s}\left(r_{s}^{B}, r_{l}^{B}\right)+\left(r_{s}^{L}-r_{s}^{B}\right) \frac{\partial y_{s}}{\partial r_{s}}+\left(r_{l}^{F}-r_{l}^{B}\right) \frac{\partial y_{s}}{\partial r_{l}} \\
& =y_{s}\left(r^{B}, r^{B}\right)+\left(r_{s}^{L}-r^{B}\right)\left(\frac{\partial y_{s}}{\partial r_{s}}+\frac{\partial y_{s}}{\partial r_{l}} \phi_{l}^{\prime}\right)
\end{aligned}
$$

and

$$
\begin{aligned}
y_{s}\left(r_{l}^{F}, r_{s}^{L}\right) & =y_{l}\left(r_{l}^{F}, r_{s}^{L}\right) \\
& =y_{s}\left(r_{s}^{B}, r_{l}^{B}\right)+\left(r_{l}^{F}-r_{s}^{B}\right) \frac{\partial y_{s}}{\partial r_{s}}+\left(r_{s}^{L}-r_{l}^{B}\right) \frac{\partial y_{s}}{\partial r_{l}} \\
& =y_{s}\left(r^{B}, r^{B}\right)+\left(r_{s}^{L}-r^{B}\right)\left(\frac{\partial y_{s}}{\partial r_{s}} \phi_{l}^{\prime}+\frac{\partial y_{s}}{\partial r_{l}}\right) .
\end{aligned}
$$

Note that demand functions are assumed identical and linear. If $\phi_{l}^{\prime}\left(r_{s}\right)>0$, then (36), (37) and (38), combined with (A3), (24) and (35), yield

$$
\begin{gathered}
y_{s}\left(r_{s}^{L}, r_{l}^{F}\right)<y_{l}\left(r_{l}^{F}, r_{s}^{L}\right), \\
y_{s}\left(r_{s}^{L}, r_{l}^{F}\right)<y_{s}\left(r_{s}^{B}, r_{l}^{B}\right)=y_{s}\left(r^{B}, r^{B}\right)=y_{l}\left(r^{B}, r^{B}\right) \text { and } \\
y_{l}\left(r_{l}^{F}, r_{s}^{L}\right)>y_{s}\left(r_{s}^{B}, r_{l}^{B}\right) .
\end{gathered}
$$

In the same way, if $\phi_{l}^{\prime}\left(r_{s}\right)<0$, then

$$
y_{s}\left(r_{s}^{L}, r_{l}^{F}\right)>y_{l}\left(r_{l}^{F}, r_{s}^{L}\right), \quad y_{s}\left(r_{s}^{L}, r_{l}^{F}\right)>y_{s}\left(r_{s}^{B}, r_{l}^{B}\right) \quad \text { and }
$$

$y_{l}\left(r_{l}^{F}, r_{s}^{L}\right)<y_{s}\left(r_{s}^{B}, r_{l}^{B}\right)$.

Combining these results, under (A3) and (35),

$$
\left\{\begin{array}{l}
y_{s}\left(r_{s}^{L}, r_{l}^{F}\right)<y_{s}\left(r^{B}, r^{B}\right)=y_{l}\left(r^{B}, r^{B}\right)<y_{l}\left(r_{l}^{F}, r_{s}^{L}\right) \\
y_{l}\left(r_{l}^{F}, r_{s}^{L}\right)<y_{s}\left(r^{B}, r^{B}\right)=y_{l}\left(r^{B}, r^{B}\right)<y_{s}\left(r_{s}^{L}, r_{l}^{F}\right)
\end{array}\right.
$$

$\phi_{l}^{\prime}\left(r_{s}\right) \gtrless 0$ or $\frac{\partial y_{t}}{\partial r_{\tau}}+r_{t} \frac{\partial^{2} y_{t}}{\partial r_{t} \partial r_{\tau}} \gtrless 0$.

(II) $\frac{\partial y_{t}}{\partial r_{\tau}}<0 \quad t, \tau \in\{s, l\} ; t \neq \tau$

In the same way as the case of (41), the following volumes are obtained:

$$
\begin{aligned}
& \left\{\begin{array}{l}
y_{s}\left(r^{B}, r^{B}\right)=y_{l}\left(r^{B}, r^{B}\right) \\
y_{s}\left(r_{s}^{L}, r_{l}^{F}\right)=y_{l}\left(r_{l}^{F}, r_{s}^{L}\right.
\end{array}\right) \\
& \text { or } \frac{\partial y_{t}}{\partial r_{\tau}}+r_{t} \frac{\partial^{2} y_{t}}{\partial r_{t} \partial r_{\tau}} \gtrless 0 .
\end{aligned}
$$

$\phi_{l}^{\prime}\left(r_{s}\right) \gtrless 0$ or $\frac{\partial y_{t}}{\partial r_{\tau}}+r_{t} \frac{\partial^{2} y_{t}}{\partial r_{t} \partial r_{\tau}} \gtrless 0$.

\section{CONCLUSION}

This paper has provided a game-theoretic analysis of the term structure of interest rates, by means of applying the theories and concepts of Bertrand and Stackelberg pricesetting games. In the paper, short- and long-term interest rates and their optimization have been investigated in the light of the equilibrium properties of these games. The main results are given as (21) and (24) in the third section, 
(34) in the fourth section, as well as (41) and (43) under identical, linear demand functions. These sections have also emphasized the crucial roles of the reaction function of long-term interest rate.

\section{REFERENCES}

Bertrand, J.L.F. 1883. Théorie des richesses: Revue de théorie mathématique de la richesse sociale, par léonwalras, et recherches sur les principles mathématiques de la théorie des richesses. Journal des Savants, $67: 499-508$.

Cournot, A.A. 1838. Recherches sur les principes mathématiques de la théorie des richess. Paris, FR : Chez L. Hachette.

Cox, J.C., Ingersoll Jr, J.E., \& Ross, S.A. 1985. A theory of the term structure of interest rates. Econometrica: Journal of the Econometric Society, 53(2): 385-407. DOI : 10.2307/1911242

Freixas, X., \& Jean-Charles, R. 2008. Microeconomics of banking. Massachusetts, MA: The MIT Press.

Matsumura, T. 1998. A two-stage price-setting duopoly: Bertrand or stackelberg. Australian Economic Papers, 37(2): 103-118. DOI:10.1111/1467-8454.t01-1-00001

Matthews, K., \& Thompson, J. 2008. The economics of banking. Chichester, UK: Wiley.

Okuguchi, K. 1999. Cournot and Stackelberg duopolies revisited. Japanese Economic Review, 50(3): 363-367. D0I: $10.1111 / 1468-5876.00125$

Puu, T., \& Sushko, I. 2002. Oligopoly dynamics: Models and tools. Berlin, DE: Springer. DoI:10.1007/978-3-540-24792-0

Sargent, T.J. 1972. Rational expectations and the term structure of interest rates. Journal of Money, Credit \& Banking, 4(1): 74-97. DOI: 10.2307/1991403

Stackelberg, H.V. 1934. Marktform und gleichgewicht. Wien, AT: Springer.

Vives, X. 2001.Oligopoly pricing: Old ideas and new tools. Massachusetts, MA: The MIT Press.

— This article does not have any appendix. - 